Vanira Matos Pessoa ${ }^{1}$ Raquel Maria Rigotto ${ }^{2}$

\title{
Agronegócio: geração de desigualdades sociais, impactos no modo de vida e novas necessidades de saúde nos trabalhadores rurais*
}

\author{
Agribusiness: Generating social inequalities, impacts on way of \\ life, and new health needs among rural workers
}

${ }^{1}$ Doutoranda em Saúde Coletiva, Departamento de Saúde Comunitária, Núcleo Trabalho, Meio Ambiente e Saúde para a Sustentabilidade, Universidade Federal do Ceará, Fortaleza, CE, Brasil.

2 Professora Adjunta, Departamento de Saúde Comunitária, Núcleo Trabalho, Meio Ambiente e Saúde para a Sustentabilidade, Universidade Federal do Ceará, Fortaleza, CE, Brasil.

*Artigo elaborado com base na dissertação de mestrado de Vanira Matos Pessoa intitulada Abordagem do Território na Constituição da Integralidade em Saúde Ambiental e do Trabalhador na Atenção Primária a Saúde, defendida em 2010 na Universidade Federal do Ceará.

Este trabalho não foi publicado em nenhum evento científico.

A pesquisadora Vanira Matos Pessoa foi bolsista do CNPq durante a realização da pesquisa, que contou com o apoio do Ministério da Saúde. Projeto $n^{\circ}$

$13407 * 3$.

Contato:

Vanira Matos Pessoa

Universidade Federal do Ceará (UFC), Departamento de Saúde Coletiva/ FAMED

Rua Professor Costa Mendes, 1608 - Bloco Didático - 5a andar, Rodolfo Teófilo, Fortaleza-CE, Brasil CEP: 60.430-140

E-mail:

vanirapessoa@gmail.com

\section{Resumo}

O artigo aborda as necessidades de saúde dos trabalhadores rurais do agronegócio no Ceará, Brasil. O Estado tem adotado um modelo de produção centrado no monocultivo irrigado de frutas para exportação que tem gerado transformações no modo de vida das comunidades, principalmente dos trabalhadores rurais. A pesquisa é qualitativa, do tipo pesquisa-ação, realizada em 2010 na Chapada do Apodi com a participação de quatorze sujeitos: trabalhadores de uma equipe de saúde da família (médico, enfermeiro, agente comunitário de saúde, auxiliar de enfermagem), dois usuários do Sistema Único de Saúde (SUS), auxiliar de serviços gerais, trabalhador rural do agronegócio, presidente da associação dos trabalhadores rurais, conselheira municipal de saúde, vereador, professora e dois representantes dos movimentos sociais. Para proceder à interpretação das falas, utilizou-se a análise do discurso, que evidenciou um contexto de vulnerabilidade socioambiental, com repercussões negativas sobre a produção, a saúde e o modo de vida. Apontou, também a insuficiente ação das políticas públicas no enfrentamento da exploração do trabalho, a contaminação ambiental e os problemas à saúde humana, como os causados pelos agrotóxicos. O contexto requer uma atuação do SUS no reconhecimento das necessidades de saúde dos trabalhadores rurais nos territórios locais.

Palavras-chaves: saúde do trabalhador; agronegócio; Sistema Único de Saúde; determinação das necessidades de saúde; agrotóxicos.

\begin{abstract}
The present study investigated the healthcare needs of agribusiness rural workers in the state of Ceará, Northeastern Brazil. Focused on irrigated fruit monoculture for export, the production model of the region has brought about profound changes in communities, notably on rural workers' way of life. This qualitative study adopted action research methodology and was conducted in 2010, when 14 residents of Chapada do Apodi were interviewed. Among them, four were members of a Family Health Strategy team (a doctor, a nurse, a community health agent, and a nursing assistant), two users of the Unified Healthcare System (SUS), a janitor, a rural worker employed in the agribusiness, the president of the rural workers' association, a representative of the municipal health department, a town councilor, a teacher, and two participants of social movements. The results of discourse analysis revealed a situation of socio-environmental vulnerability with negative repercussions on production, health, and life style. It also showed that public policies against labor exploitation, environmental damage, and human health issues, such as pesticide intoxication, are not sufficiently enforced. This situation calls for SUS actions to recognize the healthcare needs of local rural workers.
\end{abstract}

Keywords: worker's health; agribusiness; Unified Health Care System; determination of health care needs; pesticides. 


\section{Introdução}

[...] as pessoas que vêm de fora exploram a nossa situação sem limite, sem nenhuma responsabilidade, e hoje nós estamos sofrendo[...] (grupo de pesquisa)

O crescimento econômico brasileiro, entendido por muitos como gerador de melhoria de qualidade de vida, tem fomentado a expansão das fronteiras agrícolas, o agronegócio de soja, cana, celulose, carne, camarão e frutas. Isso acarreta a incidência pouco integrada de numerosos projetos setoriais sobre os territórios, propiciando o uso intensivo dos bens naturais e favorecendo a reprodução das desigualdades regionais e sociais (RIGOTTO; AUGUSTO, 2007).

Fernandes (2008, p. 48) destaca que o "agribusiness [agronegócio] consiste num complexo de sistemas que compreende agricultura, indústria, mercado e finanças". O autor refere ainda que o movimento desse complexo e suas políticas formam um modelo de desenvolvimento econômico controlado por corporações transnacionais que trabalham com um ou mais commodities e atuam em diversos outros setores da economia (FERNANDES, 2008).

O agronegócio tem se expandido no Nordeste do Brasil, especialmente no Ceará, centrado no monocultivo irrigado de frutas para exportação, ao lado da geração de empregos, mas tem ensejado consequências sobre a produção associadas à exploração do trabalho de moradores e migrantes e à contaminação ambiental, promovendo impactos na saúde humana, ocasionando mortes, intoxicações agudas e efeitos crônicos dos agrotóxicos, entre outros agravos. Marinho (2010) refere que no Ceará, segundo os dados do Sindicato da Indústria de Defensivos Agrícolas em relação às vendas de agrotóxicos de 2005 a 2009, ocorreu um aumento de 100\%, passando de 1.649 toneladas de produtos comerciais de todas as classes, em 2005, para 3.284 toneladas em 2009. Na Chapada do Apodi/ Ceará, estudo de Costa (2006) evidenciou a presença de organofosforados (39\%), de derivados do ácido fenoxiacético (14\%), de piretroides (12\%), carbamatos (7\%), organoclorados (4\%). Neste manuscrito, consideramos agrotóxicos e afins conforme a definição do artigo $2^{\circ}$ da Lei $n^{\circ} 7.802$ (BRASIL, 1989):

Produtos e os agentes de processos físicos, químicos ou biológicos, destinados ao uso nos setores de produção, no armazenamento e beneficiamento de produtos agrícolas, nas pastagens, na proteção de florestas, nativas ou implantadas, e de outros ecossistemas e também de ambientes urbanos, hídricos e industriais, cuja finalidade seja alterar a composição da flora ou da fauna, a fim de preservá-las da ação danosa de seres vivos considerados nocivos; substâncias e produtos, empregados como desfolhantes, dessecantes, estimuladores e inibidores de crescimento.
Estes processos de transformação territorial requerem a criação de competências locais que possibilitem a atuação na fase de elaboração dos projetos e durante sua implementação, como também a posteriori, por meio de análise permanente da situação de saúde da população e dos trabalhadores rurais, no caso do agronegócio. Então, para o Sistema Único da Saúde (SUS), uma questão central diante dos novos impactos do ambiente na saúde humana é: quais são as necessidades de saúde dos trabalhadores rurais do agronegócio?

Nessa perspectiva, surge uma variedade de situações do ponto de vista do entendimento do conceito de necessidades de saúde. Campos e Bataiero (2007, p. 609) fizeram uma análise da produção científica brasileira desde a década de 1990 até 2004 e sistematizaram em três categorias as concepções encontradas: Oferta/demanda de ações nos serviços de saúde - associavam necessidades de saúde "às necessidades de consumo de serviços de saúde"; administração/planejamento de serviços de saúde - apresentavam as necessidades de saúde "como instrumento para o planejamento de serviços e ações de saúde"; necessidades de saúde entendidas no âmbito abstrato e no operacional do conceito,. na perspectiva da organização da produção de serviços de saúde ou de processos de trabalho, com a finalidade de ampliação do objeto de atenção em saúde.

Apesar das categorias apresentadas, os autores consideraram que $100 \%$ dos trabalhos publicados referiam-se a necessidades de saúde institucionalmente determinadas, que prescindem da leitura de carências dos indivíduos que ocupam o território de abrangência dos serviços de saúde, evidenciando que os serviços estão abordando necessidades de saúde enquanto precisão de cuidado de agravos (CAMPOS; BATAIERO, 2007). A última categoria proposta serve-nos como guia na análise do contexto que se descortina na abordagem a saúde pela Atenção Primária à Saúde (APS) no campo, contemplando a saúde do trabalhador na perspectiva da saúde coletiva. Considerando o exposto, objetivamos discutir como têm sido produzidas novas necessidades de saúde, bem como os impactos no modo de vida dos trabalhadores rurais no nordeste brasileiro a partir da expansão do agronegócio.

\section{Metodologia}

Este estudo se insere no campo das Ciências Sociais e da Saúde, consistindo em uma pesquisa de natureza qualitativa do tipo pesquisa-ação que, segundo Thiollent:

[...] é um tipo de pesquisa social com base empírica que é concebida e realizada em estreita associação com uma ação ou com a resolução de um problema 
coletivo e no qual os pesquisadores e participantes representativos da situação ou do problema estão envolvidos de modo cooperativo e colaborativo. (THIOLLENT, 2008, p. 16)

A região de interesse situa-se na fronteira entre o Ceará e o Rio Grande do Norte, com foco na Chapada do Apodi-Ceará, no município de Quixeré, por ser um território com profundas transformações na última década a partir da instalação de grandes empresas de fruticultura irrigada para exportação. A implantação dos empreendimentos agrícolas contribuiu para diversos processos de mudanças no território pela inserção do modo de produção empresarial, estabelecendo outros tipos de relações e vínculos com o trabalho, com impactos sobre a saúde e o ambiente. Há uma mudança do modo de produção na Chapada, que anteriormente era caracterizado por atividades como a agropecuária e o extrativismo vegetal e mineral, realizadas em pequenas e médias propriedades, como o cultivo das lavouras de algodão, milho e feijão por pequenos produtores, passando para um modelo mecanizado de agricultura, centrado na monocultura, característico do agronegócio (COSTA, 2006).

Para compor o grupo de pesquisa, privilegiamos a participação social e a necessidade de ser um grupo de pessoas representativas, no território local, das políticas públicas, do poder público e dos movimentos sociais. Outro aspecto considerado foi o interesse destes agentes locais em debater/agir diante das questões referentes à inter-relação trabalho-ambiente-saúde.

O estudo envolveu 14 sujeitos, aos quais se denominou "grupo de pesquisa". Para seleção dos sujeitos do setor da saúde, priorizamos a equipe mínima de saúde da família, recomendada pela Política Nacional de Atenção Básica (BRASIL, 2006), com atuação tanto na zona rural, como urbana, inclusive a auxiliar de serviços gerais. Em relação à educação e aos movimentos sociais, solicitamos que identificassem e indicassem o representante. Quanto aos usuários do SUS, utilizamos a premissa de ser morador da zona rural e já ter utilizado o serviço de saúde lo$\mathrm{cal}$, e foram identificados pelos movimentos sociais e o trabalhador rural foi identificado pela associação dos trabalhadores rurais. Os sujeitos que representaram a Associação, o Conselho de Saúde e a Câmara Municipal são as únicas pessoas existentes na comunidade com essas responsabilidades. Para todos os sujeitos também foi considerada a disponibilidade para participar da pesquisa.

Por conseguinte, o grupo ficou assim constituído: equipe de saúde da família (médico, enfermeiro, agente comunitário de saúde, auxiliar de enfermagem), dois usuários do SUS residentes no campo, um trabalhador rural do agronegócio, o presidente da as- sociação dos trabalhadores rurais, uma conselheira municipal de saúde, um vereador, uma auxiliar de serviços gerais, uma professora da escola municipal e dois representantes dos movimentos sociais.

Realizamos este estudo em 2010, com encontros diurnos de duração média de oito horas, totalizando 44 horas, realizados a cada 21 dias no formato de oficinas temáticas - social, trabalho e ambiental utilizando-se da elaboração de mapas cartográficos. Para efeito deste manuscrito, recortamos alguns aspectos relacionados à categoria trabalho. Em relação à elaboração do mapa do trabalho, solicitamos ao grupo que identificasse os seguintes itens: onde as pessoas trabalham em cada comunidade, as ocupações existentes, os trabalhadores (procedência, sexo e outros itens), como fazem o trabalho, a que condições estão submetidas nos diversos tipos de atividades identificadas, dentre outros aspectos que considerassem importante explicitar no mapa. Após este momento, o grupo apresentava o mapa e a pesquisadora lançava perguntas constituídas a partir dos elementos que eles apontavam nos mapas, utilizando a problematização proposta por Paulo Freire, entendendo que:

[...] a ação de problematizar acontece a partir da realidade que cerca o sujeito; a busca de explicação e solução visa a transformar aquela realidade, pela ação do próprio sujeito (sua práxis). O sujeito, por sua vez, também se transforma na ação de problematizar e passa a detectar novos problemas na sua realidade e assim sucessivamente. (ZANOTTO; DE ROSE, 2003, p. 48)

Para o tratamento das informações, realizamos um estudo crítico dos discursos gravados e transcritos e analisamos os elementos contidos nos mapas. Após a transcrição e a leitura das falas, em que respeitamos os discursos dos participantes, submetemos os discursos a uma categorização temática, reunindo-os em categorias de análise organizadas.

Adotamos a análise do discurso que, conforme Caregnato e Mutti (2006), possibilita a compreensão e a apreensão do sentido e não somente do conteúdo do texto, um sentido que não é traduzido, mas produzido. A análise do discurso visa à "compreensão de como um objeto simbólico produz sentidos, como ele está investido de significância para e por sujeitos" (ORLANDI, 2000, p. 26). O autor destaca ainda que:

[...] o analista do discurso [...] não interpreta, ele trabalha nos limites da interpretação, não se coloca fora da história, do simbólico ou da ideologia. Ele se coloca em uma posição deslocada que lhe permite contemplar o processo de produção dos sentidos em suas condições. (ORLANDI, 2000, p. 61)

Reiteramos que o discurso foi entendido e analisado como uma produção do grupo e não como o discurso do médico, ou do vereador, ou de qualquer 
outro participante por solicitação dos prórpios sujeitos, tendo em vista possíveis riscos a que poderiam estar submetidos se seus discursos fossem reconhecidos pela singularidade de cada um no ato de publicação da pesquisa, visto serem as únicas representações locais de cada setor. Consideramos que isto pode se constituir como um limite do estudo.

A pesquisa foi desenvolvida conforme a Resolução no 196/96, do Conselho Nacional de Saúde (BRASIL, 1996), aprovada pelo Comitê de Ética em Pesquisa da Universidade Federal do Ceará com parecer $n^{\circ}$ 14/10.

\section{Resultados e discussão}

Campos e Bataiero (2007) afirmam que, para a saúde coletiva, é fundamental considerar a reprodução social dos diferentes grupos sociais para caracterizar os variados processos saúde-doença que acometem os indivíduos. A visualização do mundo do trabalho e de suas repercussões na saúde humana pelos profissionais da APS é imprescindível para intervenções promotoras de saúde. Nesse sentido, a prática laboral dos trabalhadores do agronegócio precisa ser indagada para que haja a compreensão do fenômeno das necessidades de saúde dos trabalhadores da região, possibilitando que a política de saúde do trabalhador entrelace-se a complexas tramas que perpassam a relação humana com o trabalho.

Sabroza, Leal e Buss (1992, p. 4) apresentam um esquema de como se dá a expressão do processo saúde-doença, destacando que:

[...] no nível individual, eles podem ser, simultaneamente, alterações fisio-patológicas para a dimensão orgânica; para o cidadão, uma representação e um papel mediado por valores culturais, e para o indivíduo singular, sofrimento. No nível das sociedades, ou formações sócio-espaciais complexas, como a nossa, eles se expressam como problemas de saúde pública, na interface entre o Estado e a Sociedade, entre o particular e o público, entre o individual e o coletivo.

Considerando o exposto, exploramos as percepções do grupo acerca de como ocorria o trabalho no agronegócio no território, procurando clarear a forma como se estabeleciam as relações de trabalho no campo e caracterizando as necessidades de saúde dos trabalhadores com base na análise da produção e do modelo de desenvolvimento econômico implantado, bem como de suas implicações para a saúde humana.

O grupo foi consensual de que a agricultura sempre foi importante para a população da região e que, hoje, o agronegócio, pela geração do emprego, consiste na principal fonte de renda local, relacionando-se com a potencialidade dos bens naturais existentes, especialmente a terra. A maioria dos participantes do grupo tem a percepção de que a terra está sendo utilizada de forma inadequada pelos grandes empreendimentos agrícolas, podendo ocasionar, dentro de poucos anos, a perda da produtividade em função das agressões promovidas pelo agronegócio.

O uso dos bens naturais na prática da agricultura é essencial, não sendo possível produzir sem utilizá-los. O que está em questão são as formas como a humanidade vem desenvolvendo esse processo. A produção de alimentos no planeta, e no Ceará, na perspectiva da promoção da saúde, deveria comprometer-se com a soberania alimentar, com a garantia de melhores condições de vida para a população local e global. Dessa forma, visitar o contexto da produção agrícola nos impulsionou a indagar: quem, como e o que produz? Para quem são produzidas as frutas na Chapada do Apodi? O que comem os moradores e trabalhadores da região? Nessa perspectiva, os sujeitos apontam que:

A principal fonte de renda é a agricultura. A maior parte da população sobrevive do agronegócio, pouca gente faz a agricultura familiar.

Antes era tirar lenha [...] depois os projetos começaram a chegar [...] e hoje em dia [...] para você tirar lenha é uma dificuldade, agora você tem que ir para o fim do mundo, porque é tudo plantação, plantação, plantação, aonde sua vista alcança e esses trabalhadores, eles principalmente, estão em contato com esses maiores riscos [...] e ninguém está [...] prestando atenção para isso, nem os próprios trabalhadores.

[...] muitas [frutas] é exportada e só vai primeira qualidade. A visão desses projetos, principalmente desse grande, é exportar [...] para Europa e para fora do Brasil [...]. Os trabalhadores lá não têm o direito de comer um melão no meio da plantação. Ele não tem o direito de comer ali, às vezes, tem casos que eles deixam levar para casa [...]. As pessoas só vivem de exportar e uma fruta que a gente [...] chama de refugo [...] é essas frutas que tem defeito [que pode comer] que são mais miudinhas, às vezes, um arranhãozinho de nada, por que o melão é embalado em caixa, por exemplo, se é uma caixa de seis melões é seis melões do mesmo tamanho da mesma cor, tem que ser por tamanho, peso e tudo, [...] aí aqueles que são mais deformados, têm uma arranhadura, levou uma queda, aí já vai complicar o que é bom.

[...] mais de $30 \%$ das frutas são enterradas, jogadas no lixo [...] acho que o município, o Estado deve fazer um convênio para as empresas que estão aqui, para ser aproveitado também essas frutas, para as fábricas fazer poupas, [...] para as creches, casas de apoio, escolas e etc.

As políticas econômicas se mostram mais voltadas para atender aos interesses de setores de produção do que às necessidades fundamentais dos consumidores (SABROZA; LEAL; BUSS, 1992). Nesse sentido, a produção de alimentos está direcionada a manter alta produtividade e lucro numa lógica que atenda as exigências de mercado. Acerca da expan- 
são do agronegócio na região do estudo, uma pesquisa descreve o processo de modernização da agricultura como conservador, excludente e doloroso:

Conservador porque não provocou mudanças na estrutura fundiária, tornando a posse da terra cada vez mais concentrada. Excludente, pois a participação do trabalhador está apenas na venda da sua força de trabalho e no recebimento de um salário, pois os mesmos não dispõem de condições para participar desse processo da mesma forma que as grandes empresas, faltam-lhes terra e dinheiro. É doloroso, pois apesar de mudar a realidade de algumas pessoas, continua concentrando a riqueza para um pequeno grupo e aprofundando desigualdades já existentes e criando novas desigualdades. (COSTA, 2006, p. 70)

No caso dos trabalhadores do agronegócio do abacaxi, em Limoeiro do Norte-CE, na mesma região, há um estudo epidemiológico (ALEXANDRE, 2009) que considera negados os seus direitos e saberes, levando-os à exposição a agrotóxicos cada vez mais frequentemente. Essa negação dos direitos e a subestimação do saber dos trabalhadores estão relacionadas à desigualdade social a que se encontram submetidos, à baixa renda, à pouca oferta de emprego, à cultura de dominação, dentre outros fatores que contribuem para uma maior vulnerabilidade dos trabalhadores rurais (ALEXANDRE, 2009). Segundo essa pesquisa, entre os trabalhadores do agronegócio do abacaxi, 38 $(50,6 \%)$ têm mais de 13 anos de trabalho com agricultura, embora a maioria, 62 (82,6\%), seja de trabalhadores rurais assalariados com tempo de um a quatro anos na empresa, e 63 (83\%) são sindicalizados. Para admissão à empresa agrícola, 49 (65,3\%) realizaram exame admissional e $49(65,3 \%)$ fizeram somente o exame laboratorial de sangue, do tipo hemograma completo, antes da admissão (ALEXANDRE, 2009).

Percebe-se que a produção não está comprometida com a melhoria da qualidade de vida dos trabalhadores e moradores da região. Isso não é uma característica somente da forma como floresceu esse processo desenvolvimentista no baixo vale do Jaguaribe, pois, segundo Sabroza, Leal e Buss (1992), esse modelo apresenta uma característica bem peculiar, que é a dissociação entre crescimento econômico e o desenvolvimento social; ou seja, a expansão das forças produtivas não implica necessariamente melhoria progressiva das condições de educação, saúde e trabalho (SABROZA; LEAL; BUSS, 1992). Considerando isso, analisar os contextos locais juntamente com os agentes sociais que estão mais próximos dessas questões pode contribuir para que nasçam estratégias de base local que influenciem e tensionem por mudanças sinérgicas.

Costa (2006) refere que a integração da região da Chapada do Apodi à lógica da produção e consumo globalizado de frutas tropicais está gradativamente extinguindo a pequena produção não capitalizada, acarretando uma queda acentuada na área plantada e na produção voltada para o mercado interno e o consumo local. Cultivos tradicionalmente produzidos pela agricultura familiar, como o milho, o feijão e o algodão, estão sendo substituídos pelo melão, pela banana e pelo mamão, com toda a cadeia produtiva sob o domínio de empresários com larga experiência no ramo da fruticultura. Portanto, está mudando a cultura e o tipo de produtor, do pequeno produtor familiar não capitalizado para grandes empresários (COSTA, 2006).

Estamos nos embasando no entendimento de agricultura familiar apresentado por Schneider (2003, p. 101) que a entende "como uma estratégia de reprodução social e econômica das famílias rurais", pois acreditamos que esta perspectiva dialoga com o contexto vivido na região pesquisada.

Referente às relações sociais de produção e distribuição, ou seja, quem produz e para quem produz, Santos et al. (2007) destacam que estas são permeadas pela instabilidade, incerteza e egoísmo, exigindo uma árdua busca para conseguir garantir a existência humana, principalmente dos trabalhadores. Desse modo, estas relações não se apresentam como saudáveis e promotoras do desenvolvimento humano, pois estão alicerçadas na competição, na destruição e na incessante falta de opções, o que caracteriza as relações de trabalho capitalizadas.

\section{Trabalho no agronegócio: alternativa de sobrevivência adoecida?}

Observamos, nas visitas exploratórias, assim como também foi dito pelo grupo de pesquisa, que os trabalhadores do agronegócio são moradores locais e/ou migrantes que têm tido suas condições de vida extremante transformadas pelo modelo de produção. Em relação ao fluxo migratório dos trabalhadores rurais, atraídos pelo emprego no agronegócio, está relacionada com a instituição de um modelo produtivo que opera com profundos efeitos colaterais para a sociedade como um todo, e de modo muito particular aos trabalhadores diretamente vinculados às empresas agrícolas, como apontam os sujeitos do grupo de pesquisa em Pessoa et al. (2011).

Não tem uma casa para ter menos de seis, sete homens. Só homens, que vem da Paraíba, Maranhão, de todo canto que você possa imaginar [...] do meio do sertão. (p. 566)

Associa-se a estas mudanças na dinâmica da comunidade, a "insegurança" que os sujeitos sentem quanto ao Estado, quando se recordam que, no tempo passado, a agricultura familiar dependia da presença da chuva por falta de investimento estatal e apoio que garantisse a fixação no campo. Isso contribuiu para que, no presente, em que há estímu- 
lo ao emprego em detrimento de investimento no empreendedorismo dos pequenos produtores, algumas pessoas apresentem uma visão determinista de aceitação do agronegócio como alternativa satisfatória. Apresenta-se uma dicotomia que assevera acessar uma forma de sobrevivência, ainda que esta prejudique a vida, determinando mudanças diversificadas no modo de vida, com repercussões sobre a qualidade de vida.

Eu sei que tem a necessidade, mas também tem o descrédito de que as coisas não vão acontecer, está entendendo? Que você vai falar, mas que vai continuar do mesmo jeito, você convide a comunidade a participar de uma reunião para você ver: de cinquenta vem cinco, porque os outros dizem assim: "a gente senta, conversa e finda do jeito que o governo quer", então, tem o descrédito e claro que tem a necessidade de trabalhar [...].

Em outras palavras, no sertão do semiárido cearense havia poucas escolhas de sobrevivência há menos de duas décadas, o que obrigava os camponeses a subordinarem-se à espera da chuva e de políticas de apoio do governo. No relato seguinte, o emprego é apresentado como estratégia de sobrevivência importante para a comunidade.

[...] há vinte e cinco anos atrás eu fui trabalhar na [nome da empresa] e dá uns 25 quilômetros de bicicleta indo e vindo todo dia. E hoje, se eu botar [...] o pé fora do meu terreiro já estou dentro do projeto, para onde a gente sair se escolhe, [...] mas por outra parte acaba com nós, com o veneno medonho que a gente come, é na melancia, no melão, na banana, tudo que você come hoje e naquele tempo você plantava um pé de melancia e colhia só com a natureza mesmo sem ter o veneno e hoje, é muito bom, tem banana aí sobrando por cima, é o melão e naquele tempo você ia comer uma fruta dessa não tinha.

A troca do trabalho pelo salário, estabelecendo uma relação de empregado-empregador na agricultura em busca de garantir a subsistência, é aceita mesmo considerando que este tipo de trabalho "prejudica a vida de cada uma das pessoas que está trabalhando", explicitando que, na luta pela sobrevivência, a saúde é uma questão secundária.

[...] a única visão das pessoas que trabalham aqui hoje é o salário [...] porque aqui a mágica do emprego que nós temos é só [...] a agricultura, que dá uma importância muito grande também para os comerciantes porque esse dinheiro está vindo para os comerciantes e o [...] comércio cresce, mas vem [...] prejudicar a vida de cada uma das pessoas que está trabalhando.

Sabroza, Leal e Buss (1992) afirmam que é preciso uma nova ética no desenvolvimento, a qual é indispensável à superação da miséria e da falta de instrução em que vive grande parte da população brasileira, situação que impede a sua efetiva inserção no processo econômico e político e, portanto, o controle sobre suas condições concretas de existência, garantindo o exercício da cidadania.

Identifica-se no discurso um desconhecimento das responsabilidades do Estado e das empresas para com o território e os trabalhadores.

[...] há quinze, vinte anos atrás [...] duzentas pessoas invadiram Quixeré [...] porque aqui não tinha emprego, não tinha nada e as pessoas necessitadas mesmo, hoje [...] vê como uma situação muito boa [...] não ter essas coisas, [...] de querer invadir [...]. A gente queria era uma responsabilidade maior das empresas [...] ter digamos: um convênio das empresas com o Estado para ter uma responsabilidade maior, ter um acompanhamento para que não venha prejudicar, porque é importante, mas que não venha prejudicar tão rápido.

Quanto ao desenvolvimento local, observa-se que o impacto gerado para a economia dos comerciantes está caracterizado por uma relação de dependência com o agronegócio. Isso porque o dinheiro que circula é proveniente da existência de mão-de-obra barata, que se subordina ao agronegócio para obter poder de compra de vestuário, alimentos e produtos de higiene pessoal e do lar. A sazonalidade do trabalho e os períodos de entressafra demonstram também como se estabelece o vínculo de dependência, porquanto há trabalhadores que ficam seis meses comprando para pagar somente quando retornar às atividades na empresa. Este aspecto é abordado por Costa (2006), apresentando o seguinte entendimento:

\begin{abstract}
Os trabalhadores assalariados do campo constituem uma mão-de-obra sem qualificação e que permanece empregada em torno de cinco meses para a colheita do melão, passando o restante do ano desempregada submetendo-se a "bicos" para sobreviver. Normalmente, no mês de janeiro essa mão de obra é dispensada devido ao período invernoso, onde a colheita é reduzida em mais da metade. Tal fato reflete diretamente no comércio da Vila de Lagoinha, que durante a entressafra que corresponde de janeiro a julho, as vendas sofrem uma queda em torno de $60 \%$. Isso mostra a dependência do comércio local em relação ao trabalho assalariado na agricultura, que se mostra bastante precarizado. (p. 54)
\end{abstract}

Essas questões vão ao encontro do que Sabroza, Leal e Buss (1992) destacam no tocante à subordinação de grupos sociais inteiros a constrangimentos em consequência das dificuldades de acesso à terra, das relações de trabalho não protegidas efetivamente e das limitações de educação e conhecimentos adequados às novas práticas produtivas que se impõem. Os agentes locais percebem estas relações e destacam que já são trazidos os profissionais qualificados de outros lugares e, para os moradores, ficam os cargos que pagam os menores salários.

[...] a pessoa chega, tem certa condição, [...] compra terra começa empregar o pessoal e vai fazendo, ele já vem com o conhecimento de como fazer, geralmente traz profissionais de fora, que a maioria dos técnicos 
agrônomos são de fora [...] cidades vizinhas, que se formaram nessas escolas agrotécnicas e vem trabalhar tudo aqui, e os daqui ficam a mão-de-obra barata.

O grupo de pesquisa alude às formas de dominação e subjugo dos moradores, que são explorados de maneira desmedida pelos "colonizadores" modernos, como também à apropriação dos bens naturais locais. Os sujeitos pesquisados apontam inclusive os danos à saúde e a exploração do trabalho, que se configuram na população local inter-relacionados ao agronegócio. Os participantes reconhecem que a natureza constitui bem valioso, pelo qual há disputas diversas no mundo globalizado, e que não há divulgação da informação para a população, que acaba não valorizando a terra.

O interesse é porque esse solo daqui da chapada do nosso rio [Jaguaribe] está como se fosse o segundo solo melhor do mundo: não é nem do Brasil! [...] aí tem aquela música que diz: "tudo que se planta dá", pois essa terra tudo que se planta dá, e nós graças a Deus moramos aqui, e era para valorizarmos muito mais. Por isso que existem guerras em países aí, pessoas que brigam por causa disso, nós aqui estamos dando as terras, vendendo [...], as pessoas que vêm de fora explora a nossa situação sem limite, sem nenhuma responsabilidade e hoje nós estamos sofrendo [...] porque o índice de câncer está aumentando muito de um certo tempo para cá [...][...] várias consequências para saúde física do trabalhador encarecendo o sistema de saúde municipal.

Em relação ao desenvolvimento econômico, com a palavra, os sujeitos...

[...] você olha ao redor, você vê [...] só estou aqui há sete anos, eu vejo a diferença em termos de desenvolvimento [...] está adoecendo mais gente, tem a longo prazo, tem o desgaste, mas hoje a maioria das pessoas tem seu transporte para andar, [...] tem sua casinha boa com suas coisinhas dentro, tem seu emprego, [...] aqui tem muita gente que passa seis meses, cinco meses comprando fiado para pagar com o dinheiro sete a oito meses que vai se empregar na firma e que não tem para onde se virar. Se não for isso, se não for essa firma que vai empregar, [...] há uma diferença grande porque a maioria das casas eram de taipa, [...] que a agricultura subsistência era muita [...] dificuldade [...] de alimentação, era muito precária [...] os empregos que garantem o padrão de vida mais ou menos, tem as consequências, têm [...] a longo prazo, agora tem veneno [...] e o que seria se não tivesse essa firma? [...] era gente invadindo! Não sei o que seria, tire as firma daqui de dentro para ver se tinha outra coisa!

No relato abaixo é revelado que a exposição aos agrotóxicos, que é uma prática cotidiana no modo de produção vivido na região, acontece sem nenhuma preocupação dos órgãos públicos. O grupo destaca também a omissão dos sindicatos dos trabalhadores rurais e até mesmo o desconhecimento de quais instituições deveriam assumir a responsabilidade social por zelar pela melhoria das condições de trabalho nas empresas agrícolas.
[...] os trabalhadores estão expostos a veneno, a luz solar. Eles não têm nenhum amparo [...] apoio por conta da empresa [...] porque não existe entidade para cobrar, não existe um sindicado que vá cobrar de uma empresa para dar o protetor solar, [...] um refeitório adequado para ele fazer, ao menos, a refeição, não existe, porque a maior plantação aqui é melão, melão não tem sombra.

Pulverização aérea de agrotóxicos e comunidade: convivência imposta pelo modelo de produção agrícola

Faria, Rosa e Facchini (2009) e Araújo et al. (2007) apontam a relação dos agrotóxicos com várias doenças, principalmente intoxicações agudas, caracterizando os agroquímicos como um dos mais importantes fatores de risco para a saúde humana, além da contaminação ambiental. Estes produtos são utilizados em grande escala por vários setores produtivos e mais intensamente pelo setor agropecuário.

Com o uso intensivo desses produtos na agricultura de larga escala, principalmente nos sistemas de monocultivo, foram aparecendo resistências por parte dos organismos-alvo (pragas e vetores) a tais substâncias (SILVA et al., 2005). A resistência das "pragas da lavoura" contribuiu para o desenvolvimento de uma diversidade de novos produtos, como também a utilização de variadas técnicas de aplicação. Dentre as técnicas, destacamos uma, intensamente utilizada no Ceará, que é a pulverização aérea. Além dos trabalhadores, as comunidades são obrigadas a conviverem com os "venenos" que são lançados ao ar pelas empresas. Diante desse contexto, indagamos: a que riscos está exposta a população do entorno das empresas agrícolas? Há estudos que apontam associações estatísticas positivas entre a exposição humana a agrotóxicos e problemas de saúde, tais como aumento de certos tipos de câncer de mama e/ou do trato reprodutivo, redução da fertilidade masculina, anormalidades no desenvolvimento sexual, entre outros (MEYER; SARCINELLI; MOREIRA, 1999).

\section{A doença como perda da oportunidade de emprego para os trabalhadores rurais do melão}

Nas asserções seguintes há evidências do desconhecimento das responsabilidades legais dos órgãos públicos fiscalizadores, sendo o INSS a única instituição reconhecida como atuante junto aos trabalhadores e à empresa. Não há sequer o conhecimento acerca de qual órgão ampara a legislação trabalhista e de quem deve assumir as responsabilidades em relação à atenção à saúde dos trabalhadores, menos ainda no que se refere às condições de trabalho na empresa.

Até para se consultar é complicado, [...] porque se [...] levar o atestado de doente, como é por safra [...]. Eu sou contratada por seis meses, eles me demitem; quando vem a outra safra eles olham até quantos 
atestados você botou, porque ele vai botar aquele que não colocou nenhum [atestado].

[...] o médico que o examinou dá um atestado [...], embora seja recriminado pelo médico da firma e o patrão, [...] de qualquer maneira os trabalhadores agrícolas têm o INSS que [...] dá um amparo [...] se precisar de quinze dias, trinta dias.

A maior assistência que tem ao trabalhador, aqui, é em termo curativo, preventiva não tem nenhum! Vou deixar bem claro, curativo porque o INSS cobra, ele cobra isso do dono da empresa, [...] e se ele tiver algum dano no trabalho, ele vai ser atendido, realmente vai ser curativa, não vai ser preventivo não. O INSS está ali para cobrar, mas tirou isso não tem nenhuma prevenção, tem [...] em termos de vacina [...] eles visam [...] o empregado [...] vacinado contra o tétano, se houver um corte não vai haver um risco do tétano [...]. Eu acho que tem até um documento que diz que eles são obrigados a ter que vacinar os trabalhadores, porque quando vem a fiscalização parece que eles tem que comprovar que eles foram vacinados. É por isso que eles até ligam pedindo, talvez seja até o INSS, alguma coisa desse tipo que cobre.

\section{Agricultura familiar: representações no imaginário coletivo}

O grupo de pesquisa nomeou três formas distintas de compreensão em relação à agricultura praticada na região. Primeiramente, trouxeram a ideia da agricultura familiar como um modelo de produção vinculado a uma estrutura de família, que planta para a subsistência. Um segundo aspecto é o entendimento dos pequenos projetos irrigados, que chegam a empregar uma média de 20 pessoas, como "agronegócio", com o diferencial de que empregam os trabalhadores por um período de tempo maior quando comparados ao agronegócio. E, por fim, o agronegócio, conforme o conceito já apresentado anteriormente, em que o emprego é vinculado a empresas. Entretanto, vale dizer que as culturas provenientes da agricultura familiar são produtos utilizados na alimentação.

[...] a agricultura familiar é ali, família, restrito aquele pedaço de terra que planta feijão, arroz o milho $[\ldots]$.

Agricultor é isso aí, só que quando a gente fala de agronegócio não levamos em conta só os projetos grandes, mas tem pequenos projetos que [...] empregam 20 pessoas, 15 pessoas e empregam por muito tempo, quer dizer é importante. [...] tem de melancia a tomate, não é uma empresa $\mathrm{X}$ uma $\mathrm{Y}$.

Há divergências no grupo quanto à compreensão da agricultura familiar, que figura no simbólico como um método de produção ligado à subsistência e arcaico, em que as pessoas não podiam acessar a escola porque os filhos deviam se submeter a cultivar a terra como os pais. Mesmo com a divergência de opiniões, há a percepção de que é melhor ter o próprio negócio do que ser empregado. No entanto, a forma tradi- cional de agricultura que o sertanejo conheceu não é a mais desejada e percebe-se que há uma confusão quanto ao entendimento do que é agricultura familiar. O grupo destaca também que a prática da agricultura familiar está diretamente relacionada ao amor à terra, e que há um processo em curso de mudança cultural em que foi se constituindo a perda dessa identidade, despertando entre os jovens o desejo de outras profissões não relacionadas ao cuidado com a terra.

[...] para sobreviver da agricultura as pessoas têm que ter amor a essa terra [...] e nós temos que cuidar dela, porque [...] a maioria dos filhos, aqui, não quer ser agrônomo, não querem ser agropecuário vão querer ser outra coisa. [...] vai querer ser uma secretária, uma médica, uma veterinária é sobreviver de coisa melhor, não querem viver de agricultura.

É melhor você trabalhar para dar renda para você mesmo. Mas eu estou falando de voltar para cultura de antigamente como minha mãe [...] não estudava, porque ela tinha que ajudar: plantando e colhendo [...] feijão e algodão, eu não vou querer isso para mim, $[\ldots]$ quero uma coisa melhor, eu não quero ficar lá plantando e colhendo feijão.

[Agricultura familiar] seria para os agricultores, [...] se teu pai [...] tiver um recurso garantido [...] para fazer esse plantio, para trabalhar, não vai impedir você de estudar, eu creio que não vai impedir! E você, com teu pai e a família vai viver muito melhor do que se tiver empregado, trabalhando, recebendo só um salário para sustentar a família [...].

Agricultura familiar, a pessoa tem seu próprio negócio. Familiar por que estou produzindo para mim mesmo, mas isso não quer dizer que a família vai estar lá dentro. [...] Não vai ter carteira assinada [...] não vou tirar seguro desemprego [...].

Além da compreensão da agricultura familiar como um meio de sobrevivência que só garante a subsistência, também se alude à dimensão cultural da mudança advinda após o estabelecimento da relação emprego-empregado, que o "desresponsabiliza" diante de um todo. Para que haja uma agricultura familiar sólida no sertão, há que se desconstruir a percepção coletiva do esforço sem medidas, do trabalho árduo sem retorno, que perdura em razão das experiências vividas no passado recente.

Mas agora tem muito da cultura daqui [...]. Você acha que é melhor para mim ser empregado de carteira assinada, [...] passando o sábado e o domingo bebendo, do que eu começar a fazer uma agricultura, aqui, em um pedacinho meu, que eu vou ser responsável sábado e domingo? Não posso nem sair de casa, vou ter que ter gasto para lá e para cá, vou ter que plantar, aguar [...]. A cultura daqui hoje é outra, devido até à questão da fábrica, [...] o povo [...] com todas as consequências [...] está achando muito melhor desse jeito, "eu ser empregado", "eu vou no dia que eu quero", [...] não são todos, mas a maioria.

Uma questão fundamental identificada é que a expansão do agronegócio está imbricada à falta de investimento na agricultura familiar. Não há uma po- 
lítica de apoio ao camponês auxiliando-o a produzir e garantir a sobrevivência, o que impulsionaria transformações no território. Estas são alavancadas pelo descaso com os pequenos produtores rurais, que vai desde a falta de garantia ao acesso à informação acerca das técnicas de cultivo mais adequadas até o financiamento, passando por um elemento central, que é o analfabetismo presente, que torna o trabalhador rural presa fácil dos estelionatários, sendo vítimas de roubos singulares por esses que se utilizam da boa-fé e da honestidade tão peculiares do sertanejo.

[...] muitos agricultores têm suas terras, tem três, quatro quintais de terras, não sabem que tem esses recursos do governo federal, que poderiam abrir seu próprio negócio, que seria muito melhor [...] as pessoas são desinformadas [...].

[...] tem vontade de fazer, mas não tem aqueles critérios [...] para poder adquirir o recurso, às vezes, a quantidade de terra não é suficiente para que ele consiga o empréstimo. [...] existe o Banco do Nordeste [...] só que existe um bocado de burocracias e que o pequeno agricultor não tem informação e as pessoas não chegam para capacitar essas pessoas [...] como seria bom que essa reunião que temos aqui também se tivesse para os pequenos agricultores para saber o caminho de buscar seus recursos, quem tem hectares férteis, tem muitos aqui que tem, mas fazem é vender porque não sabe ir buscar.

[...] aqui nós temos mais ou menos $50 \%$ de agricultores que têm suas terras, que criava [...] uma vaquinha [...] ia pegar seu dinheiro no Banco do Nordeste tinha uns esperto lá que tirava seis mil, mas só passava três mil [para o agricultor], para comprar uma vaca $[. .$.$] ovelha [\ldots]$ plantar milho, ficava com três mil [...]. Não sei porque a falta de fiscalização. [...] ele [estelionatário] não vendia, passava para o banco dizendo que vendia para o agricultor. Na hora lá, no banco [o agricultor] [...], passava seis mil, o cara ainda ficava com os três mil e o garrote ficava para ele, não ficava para o agricultor [...].

O grupo considera que não há uma política eficaz de apoio ao pequeno produtor, o que concorda com o apontado por Costa (2006), que refere que todo o potencial hídrico disponível está no subsolo, o que dificulta aos pequenos produtores ampliar suas lavouras, pois a maioria não dispõe de recursos para perfurar poços profundos com fins de irrigação.

Sabroza, Leal e Buss (1992) destacam que a valorização da informação, possibilitando aos indivíduos acessar o conhecimento acumulado pela sociedade, contribuirá para a definição de estratégias de produção autônomas, e não para definir padrões de consumo. Reiteram também que, para se viabilizar a possibilidade de modos de vida que garantam a produtividade, a autonomia e a integridade, há que se promover o acesso à informação diversificada e atualizada (SABROZA, 2006).

[...] as pessoas que têm terras aqui sofre e está vendendo suas terras e que no futuro não vai ter mais nada para as pessoas [...] na Chapada do Apodi, um hectare de terra hoje está valendo no Banco do Nordeste três mil reais, o pequeno agricultor pega um hectare de terra e vende por mil reais, o máximo mil e quinhentos reais $[\ldots]$ a falta de conhecimento.

[...] como vou trabalhar na terra? Cadê o capital de giro para eu cortar a terra, para plantar banana? Não tem! Agora, vou fazer o quê? Vou só espiar as terras dos outros, porque eu [...] fiz os tanques, os tubos de energia para ampliar o transformador, tirar um menor e botar um melhor [...] gastei dez mil e setecentos [...] aí fiquei sem nada [...]. Estou com quatro hectares e meio arrendado com banana, eu não posso plantar, eu não tenho dinheiro.

\section{Instabilidade da vida ante o modelo de desenvolvi- mento econômico}

É sabido que a mobilidade do capital acontece com a exaustão das condições essenciais para que ele ali se estabeleça. Essas condições são essencialmente, estruturas de sustentáculo temporário para o empreendimento, isso porque o modelo de produção adotado força a exaustão dos bens naturais. Para que uma empresa agrícola se acomode confortavelmente, ela precisa de terra e água para garantir sua ascensão e competição no mercado, pois elas funcionam como substrato para o uso intensivo de agroquímicos e fertilizantes, garantindo uma safra de toneladas de frutas e, portanto, o lucro. Somado a isso, ela precisa que o Estado lhe ofereça condições essenciais, como a oferta de subsídios que lhe permitirá obter mais lucros, além, é claro, de um elemento fundamental que é a mão-de-obra. Conforme Acselrald (2004):

\begin{abstract}
O capital retiraria, portanto, boa parte de sua força contemporânea da capacidade de se deslocalizar, enfraquecendo os atores sociais menos móveis - governos locais e sindicatos, por exemplo - e desfazendo, pela chantagem da localização, normas governamentais urbanas ou ambientais, bem como as conquistas sociais. Pois por sua maior mobilidade, o capital especializa gradualmente os espaços, produzindo uma divisão espacial da degradação ambiental e gerando uma crescente coincidência entre a localização de áreas degradadas e de residência de classes socioambientais dotadas de menor capacidade de se deslocalizar. (p. 34)
\end{abstract}

Contudo, no transcorrer do tempo, em um processo autofágico, são destruídas as condições, sendo, talvez, a mais relevante para as empresas agrícolas e para as comunidades a capacidade produtiva da terra, o que promove a necessidade de migrar para outros contextos e abancar-se em outros territórios. Então, compreendemos que a introdução do pacote agrobiotecnológico reflete em grande parte o incremento de capital e a manutenção da estrutura fundiária, mantendo também precárias relações de trabalho, associado à elevação dos riscos socioambientais vinculados às atividades deste setor (CARNEIRO; ALMEIDA, 2007). Os autores destacam também que não há uma reflexão estratégica e ampla acerca do modelo agrícola no país, sendo 
estimuladas ações que podem ser consideradas como aprofundamento dos riscos e de impactos socioambientais ao Brasil (CARNEIRO; ALMEIDA, 2007).

[...] a população já sabe, todo mundo ouve falar que [...] as empresas vão todas embora que não vai ter mais empregos, que as terras não vão servir mais, todo mundo sabe, mas ficam acomodados.

[...] trabalhei cinco anos e seis meses na [empresa Y], eles têm um esquema que, [...] quando as terras ficam fracas eles compram outras terras e botam o nome de outra empresa, não sei porque isso [...] lá eu catava melão, caju, tinha até uma empresa de castanha [...] e hoje estão abandonadas essas terras. O governo federal, o Lula, isso há quatro anos atrás, mais ou menos, veio lá, para dar aos sem terras, as pessoas que não tinha terra, e foi invadido, e hoje tem um assentamento, e as terras não têm [...] como produzir [...] quer dizer enfraqueceu, [...] quando for daqui dez ou quinze anos, acho que essas terras não vai produzir tudo isso não, a Lagoinha vai ser assim, bem parecido [...], e hoje essas empresas [...] têm um bocado de terras, mas não está plantando. Mas [...] não faz um trabalho social e dá as pessoas que não tem terra para plantar na época do inverno [...] Tem muitas terras que ficam sem plantar, eles passam quatro, cinco anos para depois a terra se recuperar e começar a plantar de novo, [...] passa cinco anos plantando e passa mais cinco anos sem plantar e aí vai [...] até a terra perder sua potência, como hoje se transformou a [empresa Y], que também foi embora daqui [...], essas terras da [empresa Y] já estão abandonadas, eles já foram para outro canto, com certeza com outro nome [...].

[...] o gestor maior permitiu que as empresas viessem, [...] ele vê a questão do desemprego, da necessidade, [...] ele também não analisou o outro lado da coisa que ia acontecer [...].

Interessante assinalar que, aliadas às condições ora referidas, a empresa conta com a pouca ou inexistente ação fiscalizadora do Estado, o que a deixa agir livremente nos territórios da região.

[...] vocês podem implantar sua empresa com essas condições e tal, aí podia ser que tivesse alguma melhoria [...] nas condições de trabalho dos funcionários e o descanso para a terra, um período você planta, período de descanso da terra para que não tenha exaustão da terra. [...] não tem uma fiscalização.

[...] cabe ao poder público ir até essas empresas porque sempre falam que têm um apoio, mas que tipo de apoio têm, que a gente não está vendo, [...] tinha uma plaquinha dizendo que a empresa X e Y [...] apoiava a prefeitura. Mas de que forma ela apoia?

[...] para essas empresas virem para cá, existe uma carência [...] não sei se é dez anos ou cinco anos, não paga certos impostos. É para a empresa ser [...] implantada visando os empregos são isentos de impostos não sei quais são, seria uma boa se [...] em troca desses impostos [...], fosse algum serviço social, serviço preventivo, pensando o lado da população, seria interessante o governante, a gente começar a cobrar, acho que é todos, em vez de ser isento de impostos, [...] acrescentar [...] tem que fazer certos benefícios sociais de prevenção [...] porque é uma faca de dois gumes, [...] você não paga imposto, você dá emprego, mas você dá todas as outras consequências daquela implantação daquela firma, porque [...] não tem nenhum cuidado com as consequências, que é [...] o uso inadequado de adubo, de veneno, de agrotóxico. Quer dizer, futuramente daqui a dez, vinte anos, essas terras não irão ser produtivas [...] eles vão embora, deixa aqui o povo todo desempregado, a terra sem serventia, eles não estão visando à gente lá na frente.

[...] geração [...] de emprego [...]. O que é que ela vai me dar em volta de troco [...] quando ela for embora? Ou agora, no momento [...] tem um monte de fruta que está sendo jogada, enterrada, porque não dão para as escolas [...] para as creches, [...] porque não distribui? Não é uma pessoa ir lá tirar, era eles mesmos terem o transporte deles e deixar nas escolas.

Apesar dos sujeitos identificarem vários aspectos de degradação ambiental e das consequências futuras decorrentes do processo produtivo, continuam apontando outros bens naturais a serem explorados, o que nos infere a pensar que há dificuldades do grupo em visualizar opções além deste tipo de desenvolvimento na lógica do capital.

[...] além do solo ser muito bom nós temos também a pedra $[. .$.$] que serve para gesso, seria importante que$ viesse uma empresa para esse tipo de trabalho[...].

Precisamos estar atentos para o custo social e para o Estado de cada emprego gerado nas condições que foram relatadas neste texto. Nesse custo, há de se considerar os impostos que deixam de ser recolhidos, a oneração dos serviços de saúde pelo aumento de doenças sexualmente transmissíveis, doenças crônicas decorrentes da exposição aos agrotóxicos na população em geral, as doenças ocupacionais, o sofrimento psíquico pela instabilidade do emprego, além do impacto ambiental, algumas situações praticamente irreversíveis. Esses impactos produzem uma necessidade maior da ação estatal, que terá de recuperar danos, os recuperáveis, porque a maioria dos agravos à saúde humana e ao ambiente, por mais efetiva que seja a política de saúde e de meio ambiente, não conseguirá ser abrandada.

Injetar recursos em uma forma de produção que abarque a precaução, a prevenção, a sustentabilidade não se constitui em caminho mais ameno? Não seria mais viável economicamente e sustentável investir na própria comunidade, na capacitação permanente do pequeno produtor, fortalecendo a prática da agroecologia ou da agricultura familiar, como fala também o grupo de pesquisa?

[...] se a fábrica está cheia de agrotóxicos [...] por que não ter a agricultura familiar? [...] seria uma forma de geração de emprego, [...] ele não ficou com a terra [...] porque não tinha recursos para continuar o plantio dele, mas se a prefeitura, [...] o órgão maior [...] pode dar apoio ao pequeno agricultor [...] à agricultura familiar, ela não geraria tantos problemas de saúde [...] já diminuiria os gastos com a saúde, [...] de voltar o agricultor familiar em vez de trazer empresas grandes. 


\section{Cultura do consumo $\mathrm{x}$ perda da identidade com a terra}

Sabroza (2006) considera que os custos sociais da pauperização, do desemprego, do aumento da mobilidade populacional, de desestruturação das famílias, da perda da referência cultural e de resolubilidade dos serviços públicos já recaem pesadamente e de modo desigual sobre a sociedade brasileira. Em adição, os avanços nas condições de circulação espacial viabilizaram a urbanização acelerada e a pressão sobre as áreas com baixa densidade demográfica e o ambiente, além das pessoas passarem a ter acesso, por meio dos veículos de comunicação de massa, a novos objetos de desejo. Esse contexto é o que se apresenta para nós na apreensão do território. Nas falas que seguem percebe-se claramente como o discurso hegemônico funciona como catalisador eficaz de mudanças culturais, além de favorecer o enfraquecimento de instituições de defesa dos direitos trabalhistas, como os sindicatos.

\begin{abstract}
Os meninos geralmente falam: "eu não vou nem estudar, eu vou trabalhar na empresa X, por que vou trabalhar seis meses e vou passar seis meses ganhando sem trabalhar, vou comprar o que eu quero!"

[...] uma coisa muito importante é que o trabalho na vida pública não pode sair do incentivo [...] esse trabalho social e o incentivo é uma das coisas que levam a pessoa a uma formação melhor.
\end{abstract}

A empresa não tem nenhum trabalho [social], nem de forma educativa, nem de ajudar a comunidade em nada, não tem nada! Isso era para o sindicato da gente cobrar [...] em beneficio da comunidade, aliás, eles que cobram da gente, eles pedem cartão saúde, vacina, eles pedem que a gente vá lá com os trabalhadores, pedem para benefício próprio, mas dá para gente não!

E o sindicado dos trabalhadores poderia também estar incluído para [...] ver o projeto, não é só recolher no final do mês a contribuição!

$[\ldots]$ o sindicato [...] não existe aqui, [...] já abriu algumas vezes, à tarde, para recolher a contribuição, mas não tem trabalho efetivo [...] com os trabalhadores, [...] mostrar para o trabalhador, olha, esse caminho aqui pode ser melhor, vamos procurar esse projeto que vai beneficiar a comunidade, não existe isso aqui.

\section{Considerações finais}

Pelo exposto, evidencia-se que o modelo de desenvolvimento econômico induz e impõe transformações territoriais e no modo de vida que ensejam graves problemas de saúde ao trabalhador, caracterizando-se por relações trabalhistas sem garantia de condições de trabalho dignas, como a exposição dos trabalhadores aos agrotóxicos nos campos de plantios, além de outros, como não dispor de local adequado para as refeições. Todas essas condições interferem na qualidade de vida, impactando negativamente no estado de saúde das pessoas, gerando maior demanda de serviços assistenciais, pois há um contexto de risco que se perpetua no surgimento de doenças crônicas, dentre outras.

O desenvolvimento, entendido pelos sujeitos do grupo de pesquisa, nesse contexto de vulnerabilidade socioambiental, como sinônimo de acesso às condições básicas de vida, reflete a história de desigualdade social já antiga e agora aprofundada no Nordeste brasileiro.

Nessa perspectiva, dentro desse modelo de desenvolvimento, que aspectos de promoção da saúde podem ser conquistados? Afinal, defendemos propostas políticas e ideológicas comprometidas com a vida, como explicitado na Constituição de 1988? Se a saúde é um direito de todos e dever do Estado, de que forma o Estado propõe opções de enfrentamento e transformação desse contexto com vistas a oferecer ações de promoção da saúde e não somente de atenção à saúde dentro de uma lógica curativa?

Perceber este processo de transformação e caminhar na implantação de políticas de saúde que abordem a complexidade dos processos promotores de alterações na dinâmica comunitária, com severos impactos à saúde humana e ao ambiente, é essencial no SUS. Neste sentido, fortalecer as práticas de saúde centradas na identificação das necessidades de saúde dos trabalhadores rurais consiste em uma premissa para a Atenção Primária à Saúde (APS). Avançar no diálogo dos serviços de saúde com movimentos sociais e trabalhadores pode aproximar a compreensão das necessidades de saúde dos trabalhadores rurais, bem como planejar ações contextualizadas capazes de reconhecer o território, as pessoas e suas necessidades.

A saúde da população é a expressão singular destes processos em curso no território, pois a forma como tem se estruturado o trabalho, promovendo alterações em todo o núcleo da família, ocasiona impactos que vão além dos danos específicos e mensuráveis. Assim, é essencial para o setor da saúde discutir na perspectiva da inter-relação - promoção, prevenção, proteção, atenção e gestão - e não focalizar apenas em agravos. Além da ampliação do modo de agir, centrado nas necessidades de saúde, tendo-se como referência o território local e os seus processos de mudanças, é fundamental para o setor da saúde a constituição de uma abordagem intersetorial e integrada.

Em suma, a reestruturação do modo de viver das pessoas desencadeada pelo modelo de desenvolvimento traz para o SUS a necessidade de ancorar suas ações, compreendendo que o processo produtivo em si e os impactos à saúde dos trabalhadores não se restringem aos muros das empresas, sendo fundamental incorporar os propósitos de uma política de saúde ambiental e do trabalhador integrada no território. 


\section{Contribuições de autoria}

PESSOA, V. M.: coletou e analisou o material empírico e elaborou o manuscrito. RIGOTTO, R. M.: elaborou e revisou criticamente o artigo.

\section{Referências}

ACSELRAD, H. (Org.). Conflitos ambientais no Brasil. Rio de Janeiro: Relume Dumará, 2004.

ALEXANDRE, S. F. Estudo dos agravos à saúde dos trabalhadores expostos a agrotóxicos no agronegócio do abacaxi em Limoeiro do Norte - Ceará. 2009. 250 f. Dissertação (Mestrado em Saúde Pública)Faculdade de Medicina, Universidade Federal do Ceará, Fortaleza, 2009.

ARAÚJO, A. J. et al. Exposição múltipla a agrotóxicos e efeitos à saúde: estudo transversal em amostra de 102 trabalhadores rurais, Nova Friburgo, RJ. Ciências \& Saúde Coletiva, Rio de Janeiro, v. 12, n. 1, p. 115-130, jan./mar. 2007.

BRASIL. Lei nº 7.802, de 11 de julho de 1989. Dispõe sobre a pesquisa, a experimentação, a produção, a embalagem e rotulagem, o transporte, o armazenamento, a comercialização, a propaganda comercial, a utilização, a importação, a exportação, o destino final dos resíduos e embalagens, o registro, a classificação, o controle, a inspeção e a fiscalização de agrotóxicos, seus componentes e afins, e dá outras providências. Brasília: Presidência da República, 1989. Disponível em: < http://www.planalto.gov.br/ccivil_03/ Leis/L7802.htm>. Acesso em: 04 jun. 2012.

. Ministério da Saúde. Conselho Nacional de Saúde. Resolução nº 196, de 10 de outubro de 1996. Aprova as diretrizes e normas regulamentadoras da pesquisa envolvendo seres humanos. Brasília: Ministério da Saúde, 1996. Disponível em: <http:// conselho.saude.gov.br/resolucoes/reso_96.htm >. Acesso em: 04 jun. 2012.

. Ministério da Saúde. Secretaria de Atenção à Saúde. Departamento de Atenção Básica. Política nacional de atenção básica. Brasília: Ministério da Saúde, 2006. Disponível em: < http://bvsms.saude. gov.br/bvs/publicacoes/politica_nacional_atencao_ basica_2006.pdf $>$. Acesso em: 01 jun. 2012 .

CAMPOS, C. M. S.; BATAIERO, M. O. Necessidades de saúde: uma análise da produção científica brasileira de 1990 a 2004. Interface, São Paulo, v. 11, n. 23, p. 605-618, set./dez. 2007.

CAREGNATO, R. C. A.; MUTTI, R. Pesquisa qualitativa: análise de discurso versus análise de conteúdo. Texto \& Contexto Enfermagem, Florianópolis, v. 15, n. 4, p. 679-684, out./dez. 2006.

CARNEIRO, F. F.; ALMEIDA, V. E. S. de. Os riscos socioambientais no contexto da modernização conservadora da agricultura. Ciência \& Saúde Coletiva, Rio de Janeiro, v. 12, n. 1, p. 22-23, jan./mar. 2007.
COSTA, R. E. B. Modernização agrícola conservadora e as alterações socioespaciais no distrito de LagoinaQuixeré (CE). Limoeiro do Norte-CE. 2006. $74 \mathrm{f}$. Monografia (Especialização em Meio Ambiente)Faculdade de Filosofia Dom Aureliano Matos, Universidade Estadual do Ceará, Limoeiro do Norte, 2006.

FARIA, N. M. X.; ROSA, J. A. R. da; FACCHINI, L. A. Intoxicações por agrotóxicos entre trabalhadores rurais de fruticultura, Bento Gonçalves, RS. Revista de Saúde Pública, São Paulo, v. 43, n. 2, p. 335-344, mar./abr. 2009.

FERNANDES, B. M. Campesinato e agronegócio na América Latina: a questão agrária atual. São Paulo: Expressão Popular, 2008.

MARINHO, A. M. C. P. Contextos e contornos da modernização agrícola em municípios do Baixo Jaguaribe-CE: o espelho do (des)envolvimento e seus reflexos na saúde, trabalho e ambiente. 2010. $245 \mathrm{f}$. (Doutorado em Saúde Pública)-Faculdade de Saúde Pública, Universidade de São Paulo, São Paulo, 2010.

MEYER, A.; SARCINELLI, P. N.; MOREIRA, J. C. Estarão alguns grupos populacionais brasileiros sujeitos à ação de disruptores endócrinos? Cadernos de Saúde Pública, Rio de Janeiro, v. 15, n. 4, p. 845850, out./dez. 1999.

ORLANDI, E. P. Análise do discurso: princípios e procedimentos. Campinas: Pontes, 2000.

PESSOA, V. M. et. al. As novas necessidades de saúde nos territórios dos sertanejos do baixo vale do Jaguaribe-CE e os desafios à política pública de saúde. In: RIGOTTO, R. M. (Org.). Agrotóxicos, trabalho e saúde: vulnerabilidade e resistência no contexto da modernização da agrícola no Baixo Jaguaribe/CE. Fortaleza: Edições UFC, 2011. p. 549-583.

RIGOTO, R. M.; AUGUSTO, L. G. S. Seminário sobre saúde ambiental e saúde do trabalhador e suas interfaces com o Programa de Aceleração do Crescimento - PAC. 2007. Disponível em: http://www. justicaambiental.org.br/_justicaambiental/pagina. php?id=1770. Acesso em: 10 fev. 2010.

SABROZA, P. C. Concepções sobre saúde e doença. Curso de aperfeiçoamento de gestão em saúde. Educação a distância. Rio de Janeiro: Escola Nacional de Saúde Pública Sergio Arouca, 2006. Disponível em: <http://www.abrasco.org.br/UserFiles/File/13\%20CNS/ SABROZA\%20P\%20ConcepcoesSaudeDoenca.pdf>. Acesso em: 20 jan. 2010. 
SABROZA, P. C.; LEAL, M. C.; BUSS, P. M. A Ética do desenvolvimento e a proteção às condições de saúde. Cadernos de Saúde Pública, Rio de Janeiro, v. 8, n. 1, p. 88-95, jan./mar. 1992.

SANTOS, R. S. et al. Compreendendo a natureza das políticas do Estado capitalista. Revista de Administração Pública, Rio de Janeiro, v. 41, n. 5, p. 819-834, set./out. 2007.

SCHNEIDER, S. Teoria social, agricultura familiar e pluriatividade. Revista Brasileira de Ciências Sociais, São Paulo, v. 18 n. 51, p. 99-121, fev. 2003.
SILVA, J. M. et al. Agrotóxico e trabalho: uma combinação perigosa para a saúde do trabalhador rural. Ciência \& Saúde Coletiva, Rio de Janeiro, v. 10, n. 4, p. 891-903, out./dez. 2005.

THIOLLENT, M. Metodologia da pesquisa-ação. 16. ed. São Paulo: Cortez, 2008.

ZANOTTO, M. A. C.; DE ROSE, T. M. S. Problematizar a própria realidade: análise de uma experiência de formação contínua. Educação e Pesquisa, São Paulo, v. 29, n. 1, p. 45-54, jan./jun. 2003. 